\title{
Artificial Photosynthetic Systems for Production of Hydrogen
}

\author{
Shunichi Fukuzumi
}

Department of Material and Life Science, Graduate School of Engineering, ALCA, Japan Science and Technology Agency (JST), Osaka University, Suita, Osaka 565-0871, Japan

The rapid consumption of fossil fuels has caused unacceptable environmental problems such as the greenhouse effect, which may lead to disastrous climatic consequences. Because fossil fuels are the products of long-term photosynthesis, it is highly desirable to develop artificial photosynthetic systems for the production of renewable and clean energy such as hydrogen. This article summarizes recent advances on studies of artificial photosynthetic systems for photocatalytic production of hydrogen with hydrogenases and their functional mimics including hybrids of natural and artificial components. Because it is highly desired to convert gaseous $\mathrm{H}_{2}$ to an easily storable form, recent progress on storage of hydrogen as liquid or solid form has also been described in this article.

\section{Introduction}

Photosynthesis is an important biological process by which plants and some bacteria utilize solar energy to produce ATP and NADPH for fixation of $\mathrm{CO}_{2}$ in the Calvin cycle [1]. The solar energy has been stored as fossil fuels, which were made through photosynthesis over a billion years. As the world population grows and the standard of living improves, the world's consumption rate of fossil fuels is also rapidly growing. The combustion of fossil fuels has already led to unacceptable levels of pollution of our environment by the release of the huge amount of $\mathrm{CO}_{2}$, which has caused the green 
house effect on the earth [2]. Thus, the sustainable production of solar fuels, such as $\mathrm{H}_{2}$ from water, by artificial photosynthesis is a promising means to replace fossil fuels for long-term global energy requirements [2,3]. There has been much effort for development of artificial photosynthesis including hybrids of natural and artificial components [3-9], which is summarized in this article. Nature has optimized solar energy conversion within finely tuned molecular systems called photosynthetic reaction center proteins (RCs), in which efficient charge separation occurs with a high quantum efficiency to attain long-lived charge-separated state [1]. The Photosystem I RC protein (PSI) [10] has been combined with [NiFe]- and [FeFe]-hydrogenase enzymes $[11,12]$ to drive $\mathrm{H}_{2}$ production $[8,9]$. The hydrogenase enzymes have been replaced by $\mathrm{Pt}$ nanoclusters $[8,9]$. In addition, the RC protein has also been replaced by synthetic organic compounds, which undergo efficient charge separation with slow charge recombination [13]. Various hydrogenase functional mimics have been developed as efficient catalysts for $\mathrm{H}_{2}$ production to replace Pt nanoclusters by more earth-abundant materials [14-18].

Because $\mathrm{H}_{2}$ gas is explosive and its volumetric energy density is quite low, low-cost, energy-efficient storage of $\mathrm{H}_{2}$ as a liquid or solid form is definitely needed for stationary and portable applications in the $\mathrm{H}_{2}$-delivery infrastructure, which is also described in this article [19].

\section{Biohybrids for $\mathrm{H}_{2}$ production}

Electrons produced by the water splitting Photosystem II (PSII) are transferred to the Photosystem I (PSI) and finally to ferredoxin (Fd) [1]. Fd serves as a reducing agent to generate NADPH primarily for autotrophic carbon dioxide fixation via the CalvinBenson-Bassham (CBB) cycle [1]. Although NADPH is an indispensable reductant in living cells, it is not particularly useful as a source of stored bond energy for human activity. NADPH is the biological equivalent of $\mathrm{H}_{2}$; both are oxygen-stable, and their 
standard redox potentials are similar (the $E^{0}$ of the $\mathrm{NADP}^{+} / \mathrm{NADPH}$ couple at $\mathrm{pH}=7$ is $-324 \mathrm{mV}$, whereas the $E^{0}$ of the $\mathrm{H}^{+} / \mathrm{H}_{2}$ couple is $-414 \mathrm{mV}$ ) [20,21]. Although, the hydrogenase and PSI are not physiological redox partners, $\mathrm{H}_{2}$ production by the combination of PSI and hydrogenase is thermodynamically feasible. Okura and coworkers reported fusion of the PSI subunit PsaE from the cyanobacterium Thermosynechococcus elongatus with an $\mathrm{O}_{2}$-tolerant $[\mathrm{NiFe}]$ hydrogenase from Ralstonia eutropha H16 [22]. The hydrogenase-PSI complex displayed light-driven hydrogen production with ascorbate as an electron donor at a rate of $0.58 \mu \mathrm{mol} \mathrm{H}_{2}(\mathrm{mg}$ chlorophyll) ${ }^{-1} \mathrm{~h}^{-1}[22,23]$.

Hydrogenase can be replaced by Pt nanoclusters for the photocatalytic hydrogen production with PSI [24]. PtNPs bind readily to native PSI as shown in Figure 1a. The size of the nanoparticles was estimated to be $3.0 \pm 0.2 \mathrm{~nm}$ [25]. PtNPs form a complex with PSI in a $1.0 \pm 0.2 \mathrm{Pt}$ nanoparticle/PSI monomer; nearly 1:1 ratio. Cytochrome $c_{6}$ acts as the soluble mediator and ascorbate as a sacrificial electron donor, when visiblelight-driven $\mathrm{H}_{2}$ production occurs efficiently with the PSI/Pt nanoparticle biohybrids at a rate of $244 \mu \mathrm{mol} \mathrm{H}_{2}(\mathrm{mg} \text { chlorophyll })^{-1} \mathrm{~h}^{-1}$ [25]. Upon photoexcitation of PSI, photoinduced electron transfer occurs from the primary electron donor P700 (a dimer of chlorophyll molecules) through a series of protein-embedded donor/acceptor molecules including three [4Fe-4S] clusters, FX, FA, and FB, to the Pt nanoparticle (Figure 1b) [25]. A fully optimized PSI/molecular wire/Pt nanoparticle system with cross-linked plastocyanin (native electron donor protein to $\mathrm{P} 700^{+}$) exhibited a higher $\mathrm{H}_{2}$ production

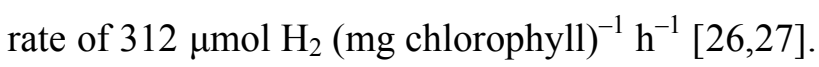




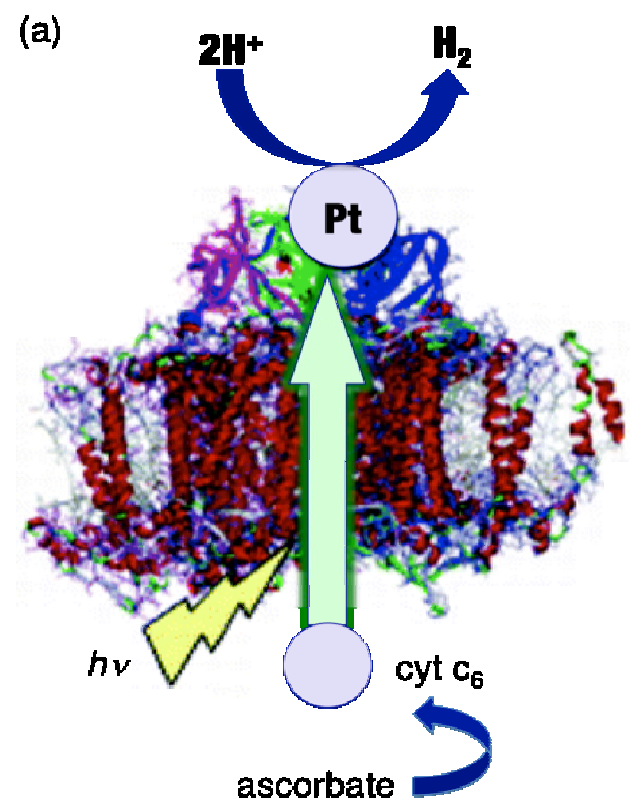

(b)

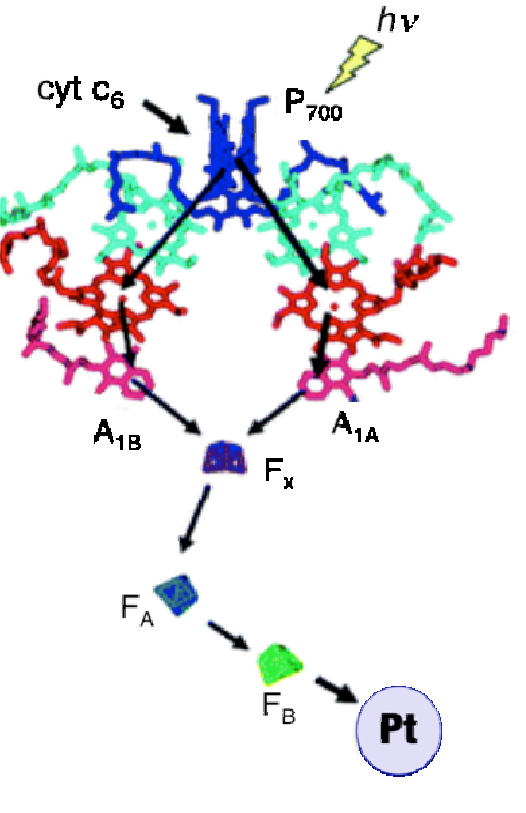

Figure 1. (a) Photocatalysis of PSI/Pt nanoparticle complexes. (b) Schematic representation of the cofactors involved in sequential electron transfer in PSI. Cytochrome $\mathrm{c}_{6}$ (shown) or plastocyanin are donors to $\mathrm{P} 700^{+}$. A Pt nanoparticle is depicted in place of the native protein acceptors of PSI, either ferredoxin or flavodoxin.

[FeFe]-hydrogenase from Clostridium acetobutylicum (CaI) has also been combined with CdS nanorods (NRs) instead of PSI for photoinduced $\mathrm{H}_{2}$ production using ascorbate as an electron donor with quantum yields $\left(\mathrm{QY}\left(\mathrm{H}_{2}\right)\right)$ of up to $20 \%$ at a $\mathrm{CaI}: \mathrm{CdS}$ NR molar ratio of 1:1, where QY $\left(\mathrm{H}_{2}\right)$ is defined as $\left(\mathrm{H}_{2}\right.$ molecules produced/photons absorbed $) \times\left(2\right.$ electrons $/ \mathrm{H}_{2}$ molecule $)$ [28]. The CdS-CaI complexes are formed by binding of CdS NRs, which are capped with negatively charged surface ligands, with $\mathrm{CaI}$ as analogs of the electron-donating protein $\mathrm{Fd}$ [28]. Photoexcitation of $\mathrm{CdS}$ is followed by electron transfer from $\mathrm{CdS}$ to a distal iron-sulfur cluster followed by transport through a series of accessory iron-sulfur clusters to the active site of $\mathrm{CaI}$ in which two electrons are reduced to $\mathrm{H}_{2}$, whereas holes are scavenged by the electron donor ascorbate $\left(\mathrm{AscH}^{-}\right)[28,29]$. 


\section{Inorganic photocatalysts for $\mathrm{H}_{2}$ production}

Both PSI and hydrogenases for photoinduced $\mathrm{H}_{2}$ production described above can be replaced by artificial components, composed of a sacrificial electron donor, an inorganic photocatalyst, and a proton reduction catalyst, which have been extensively studied since late 1970s [30-32]. A typical homogeneous photocatalytic system for $\mathrm{H}_{2}$ production using an inorganic photocatalyst is shown in Scheme 1, where photoinduced electron transfer from ascorbate to the excited state of $\left[\mathrm{Ru}(\mathrm{bpy})_{3}\right]^{2+}\left(\mathrm{bpy}=2,2^{\prime}\right.$ bipydine) occurs to produce $\left[\mathrm{Ru}(\mathrm{bpy})_{3}\right]^{+}$as a primary photogenerated reductant, which is capable of reducing a cobalt complex cobalt(II) complex with 6-(bis(bis-2-pyridyl)methoxymethane) pyridine pentadentate ligand with a fast rate (bimolecular rate constant $\left.k=5.7( \pm 0.7) \times 10^{9} \mathrm{M}^{-1} \mathrm{~s}^{-1}\right)$ [33]. For hydrogen generation, two one-electron photochemical reduction steps of the cobalt(III) complex are needed along with hydride formation and protonation [33].

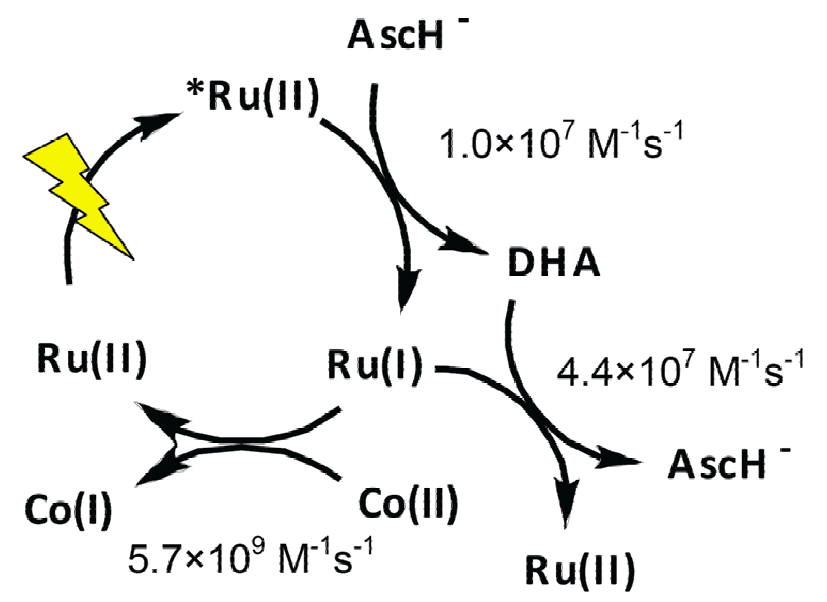

Scheme 1. Photocatalytic cycle for $\mathrm{H}_{2}$ production under visible light irradiation of the photolysis mixture containing $\left[\mathrm{Ru}(\mathrm{bpy})_{3}\right]^{2+}$, a cobalt(II) complex with 6-(bis(bis-2pyridyl)-methoxymethane) pyridine pentadentate ligand (1), and ascorbic acid. Abbreviations: $\mathrm{Ru}(\mathrm{II})=\left[\mathrm{Ru}(\mathrm{bpy})_{3}\right]^{2+}, * \mathrm{Ru}(\mathrm{II})=\left[\mathrm{Ru}(\mathrm{bpy})_{3}\right]^{2+} *, \mathrm{Ru}(\mathrm{I})=\left[\mathrm{Ru}(\mathrm{bpy})_{3}\right]^{+}$, $\mathrm{AscH}^{-}=$ascorbic acid, DHA = dehydroascorbic acid. 
A high turnover number $(\mathrm{TON}=6500)$ has been achieved for photocatalytic $\mathrm{H}_{2}$ production using (4,4'-di-tert-butyl-2,2'-dipyridyl)-bis(2-phenylpyridine-(1H))iridium(III) hexafluorophosphate $\left[\operatorname{Ir}(\mathrm{ppy})_{2}(\mathrm{dtbbpy})\right]\left[\mathrm{PF}_{6}\right]$ as a photocatalyst and triethanolamine (TEOA) as a sacrificial electron donor and a tetra-nickel-containing polyoxotungstate, $\mathrm{Na}_{6} \mathrm{~K}_{4}\left[\mathrm{Ni}_{4}\left(\mathrm{H}_{2} \mathrm{O}\right)_{2}\left(\mathrm{PW}_{9} \mathrm{O}_{34}\right)_{2}\right] \cdot 32 \mathrm{H}_{2} \mathrm{O}\left(\mathrm{Na}_{6} \mathrm{~K}_{4}-\mathrm{Ni}_{4} \mathrm{P}_{2}\right)$ as a noble metalfree molecular catalyst [34]. The excited state $\left[\operatorname{Ir}(\mathrm{ppy})_{2}(\mathrm{dtbbpy})\right]^{+} *$ was both oxidatively and reductively quenched by $\mathrm{Ni}_{4} \mathrm{P}_{2}$ and TEOA, respectively [34]. Extensive stability studies (e.g., UV-vis absorption, FT-IR, mercury-poison test, dynamic light scattering (DLS) and transmission electron microscopy (TEM)) provided evidence that the $\mathrm{Ni}_{4} \mathrm{P}_{2}$ catalyst remains homogeneous and intact under turnover conditions [34].

How a photoinduced electron-transfer reaction of a photocatalyst (a one-electron process) leads to $\mathrm{H}_{2}$ production (a two-electron process) has been clarified in $\left[\mathrm{Ru}(\mathrm{bpy})_{3}\right]^{2+}$-catalyzed light-driven $\mathrm{H}_{2}$ production from ascorbic acid using $\left[\mathrm{Rh}^{\mathrm{III}}\left(\mathrm{Cp}^{*}\right)(\mathrm{bpy})\left(\mathrm{H}_{2} \mathrm{O}\right)\right]\left(\mathrm{SO}_{4}\right)\left(\mathrm{Cp}^{*}=\eta^{5}-\mathrm{C}_{5} \mathrm{Me}_{5}\right)$ and $\left[\operatorname{Ir}^{\mathrm{III}}\left(\mathrm{Cp}^{*}\right)\left(\mathrm{H}_{2} \mathrm{O}\right)-(\mathrm{bpm}) \mathrm{Ru}^{\mathrm{II}}(\mathrm{bpy})_{2}\right]-$ $\left(\mathrm{SO}_{4}\right)_{2}$ (bpm=2,2'-bipyrimidine) as proton reduction catalysts [35]. The laser flash photolysis studies have revealed the photocatalytic mechanism as shown in Scheme 2 [35]. Photoinduced electron transfer from $\mathrm{HA}^{-}$to $\left[\mathrm{Ru}(\mathrm{bpy})_{3}\right]^{2+} *$ (a one-electron process) leads to the two-electron reduction of protons to produce $\mathrm{H}_{2}$ by disproportionation of the one-electron-reduced species of $\left[\mathrm{Rh}^{\mathrm{III}}\left(\mathrm{Cp}^{*}\right)(\mathrm{bpy})\left(\mathrm{H}_{2} \mathrm{O}\right)\right]^{2+}$ and $\left[\operatorname{Ir}^{\mathrm{III}}\left(\mathrm{Cp}^{*}\right)\left(\mathrm{H}_{2} \mathrm{O}\right)\right.$ $\left.(\mathrm{bpm}) \mathrm{Ru}^{\mathrm{II}}(\mathrm{bpy})_{2}\right]^{2+}$ to afford the two-electron-reduced metal complexes, which are protonated to give the metal hydride complexes. Hydrogen is produced by reactions of the metal hydride complexes with protons to regenerate the oxidized catalysts [35]. Thus, disproportionation of the one-electron-reduced metal complexes is responsible for the conversion from the one-electron process (photoinduced electron transfer) to the two-electron process $\left(\mathrm{H}_{2}\right.$ production). 


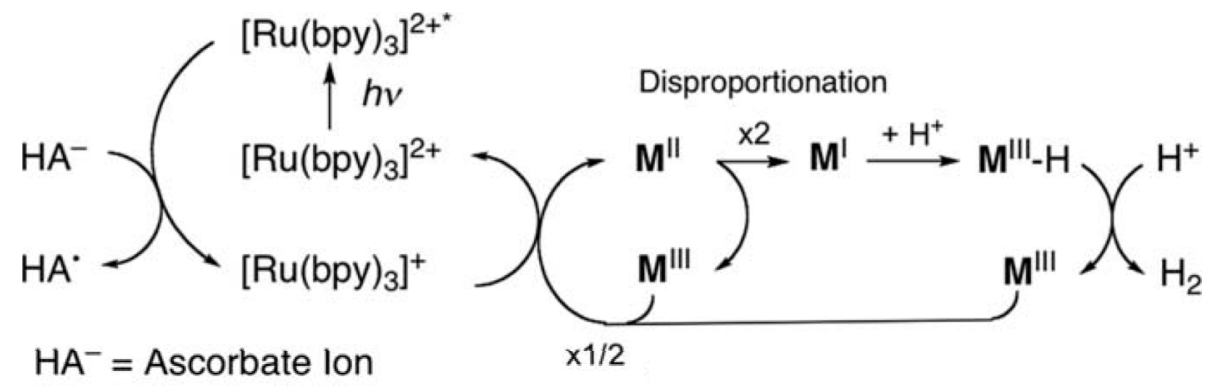

Scheme 2. Photocatalytic $\mathrm{H}_{2}$ evolution with metal complexes $(\mathrm{M}=\mathrm{Rh}$ and $\mathrm{Ir}$ complexes) by a disproportionation mechanism.

\section{Organic photocatalysts for $\mathrm{H}_{2}$ production}

The photocatalytic efficiency of $\mathrm{H}_{2}$ evolution has been much improved by using organic donor-acceptor linked molecules with a long-lived electron-transfer state [36,37], which can inject electrons directly to hydrogen-evolution catalysts without an electron mediator upon photoexcitation of the donor-acceptor linked dyads instead of using inorganic photocatalysts [38,39]. A very high quantum yield $\left(\mathrm{QY}\left(\mathrm{H}_{2}\right)=\mathrm{H}_{2}\right.$ molecules produced/photons absorbed $) \times\left(2\right.$ electrons $/ \mathrm{H}_{2}$ molecule $\left.=52 \%\right)$ and a high yield of $\mathrm{H}_{2}$ $(95 \%)$ based on an electron donor (NADH) have been achieved under photoirradiation of a deaerated phthalic acid buffer $(\mathrm{pH} 4.5,50 \mathrm{mM})$ and acetonitirle $(\mathrm{MeCN})[1: 1(\mathrm{v} / \mathrm{v})]$ mixed solution containing 9-mesityl-10-methylacridinium ion $\left(\mathrm{Acr}^{+}-\mathrm{Mes}\right)(0.10 \mathrm{mM})$, NADH (1.0 mM) and poly(N-vinyl-2-pyrrolidone)-protected platinum nanocluster (PtPVP) (0.20 mg) at $298 \mathrm{~K}$ [39]. Upon photoexcitation of $\mathrm{Acr}^{+}-\mathrm{Mes}$, the electron-transfer state $\left(\mathrm{Acr}^{-}-\mathrm{Mes}^{-+}\right)$is formed and electron transfer from NADH to the Mes ${ }^{++}$moiety of Acr-Mes ${ }^{-+}$occurs rapidly to produce $\mathrm{NADH}^{\cdot+}$ and Acr-Mes (Scheme 3). $\mathrm{NADH}^{++}$ deprotonates to produce $\mathrm{NAD}^{\circ}$, followed by fast electron transfer from NAD ${ }^{\bullet}$ to $\mathrm{Acr}^{+}-$ Mes to yield $\mathrm{NAD}^{+}$and Acr-Mes as revealed by laser flash photolysis measurements [39]. Thus, the absorption of one photon resulted in formation of two equivalents of Acr-Mes (Scheme 3). Electron injection from Acr--Mes to PtNPs with protons resulted in production of $\mathrm{H}_{2}$. Cubic PtNPs with a diameter of $6.3 \pm 0.6 \mathrm{~nm}$ exhibited the 
maximum catalytic activity for the photocatalytic $\mathrm{H}_{2}$ production [40]. The observed photocatalytic $\mathrm{H}_{2}$ production rate was virtually same as the rate of electron injection from Acr-Mes to PtNPs [40]. The rate constant of the electron injection $\left(k_{\mathrm{et}}\right)$ increased linearly with increasing proton concentration [40]. When $\mathrm{H}^{+}$was replaced by $\mathrm{D}^{+}$, the inverse kinetic isotope effect was observed for the electron-transfer rate constant $\left(k_{\mathrm{et}}(\mathrm{H}) / k_{\mathrm{et}}(\mathrm{D})=0.47\right)[40]$. The linear dependence of $k_{\mathrm{et}}$ on proton concentration together with the observed inverse kinetic isotope effect indicated that proton-coupled electron transfer (PCET) from Acr-Mes to PtNPs to form the Pt-H bond is the ratedetermining step for the photocatalytic $\mathrm{H}_{2}$ production (Scheme 4) [40].

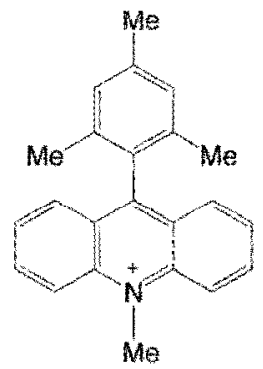

$\mathrm{ACr}^{+}-\mathrm{Mes}$

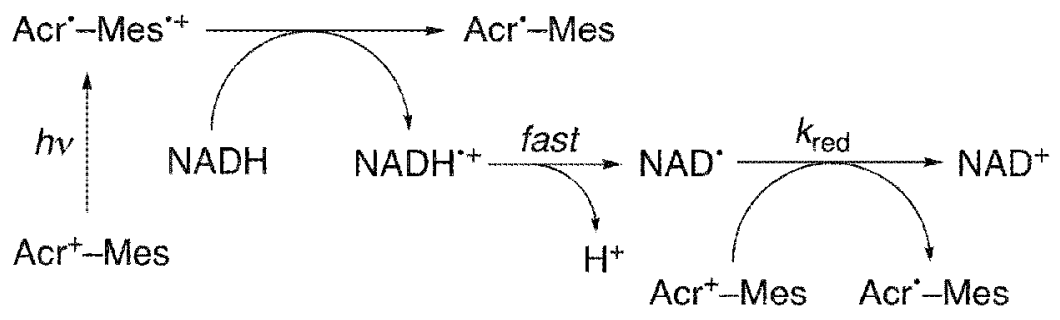

Scheme 3. Mechanism of photoinduced reduction of $\mathrm{Acr}^{+}-\mathrm{Mes}$ with NADH.

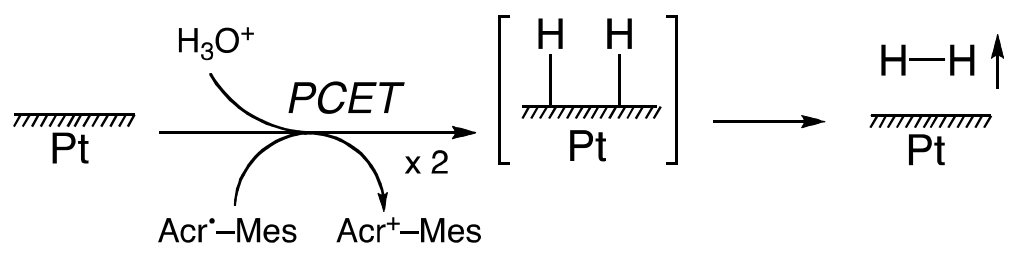

Scheme 4. PCET production of $\mathrm{H}_{2}$ with Acr--Mes on PtNPs.

When $\mathrm{Acr}^{+}-\mathrm{Mes}$ was replaced by 2-phenyl-4-(1-naphtyl)quinolinium ion $\left(\mathrm{QuPh}^{+}-\mathrm{NA}\right)$, photocatalytic $\mathrm{H}_{2}$ production with NADH and PtNPs was made possible under basic conditions ( $\mathrm{pH}$ 10) [41]. PtNPs could be replaced by RuNPs with the virtually the same 
catalytic activity for $\mathrm{H}_{2}$ production [41]. Upon photoexcitation of $\mathrm{QuPh}^{+}-\mathrm{NA}$, the electron-transfer state of $\mathrm{QuPh}^{+}-\mathrm{NA}\left(\mathrm{QuPh}^{\bullet}-\mathrm{NA}^{\cdot+}\right)$ is produced, followed by electron transfer from $\mathrm{NADH}$ to the $\mathrm{NA}^{\cdot+}$ moiety of $\mathrm{QuPh}^{\cdot}-\mathrm{NA}^{\bullet+}$, resulting in formation of two equivalents of $\mathrm{QuPh}^{\circ}-\mathrm{NA}$ via deprotonation of $\mathrm{NADH}^{\cdot+}$ and the subsequent electron transfer from $\mathrm{NAD}^{\circ}$ to $\mathrm{QuPh}^{+}-\mathrm{NA}$ (Scheme 5). Electron transfer from the photogenerated $\mathrm{QuPh}^{\circ} \mathrm{-NA}$ to RuNPs resulted in $\mathrm{H}_{2}$ evolution even under basic conditions. The rate of electron transfer from $\mathrm{QuPh}^{\circ}-\mathrm{NA}$ to RuNPs is much faster than the rate of hydrogen evolution. RuNPs with the size of $4.1 \mathrm{~nm}$ exhibited the highest $\mathrm{H}_{2}$ evolution rate normalized by the weight of RuNPs [41]. The photocatalytic $\mathrm{H}_{2}$ evolution with RuNPs $(4.1 \mathrm{~nm})$ under $\mathrm{pH} 10$ conditions indicated that turnover frequency and turnover number normalized by the number of surface Ru atoms were as high as $1050 \mathrm{~h}^{-1}$ and 300, respectively [41]. In the case of $\mathrm{Acr}^{+}-\mathrm{Mes}$, electron transfer from Acr-Mes to PtNPs requires the assistance of a proton and the rate of the protoncoupled electron transfer increases with increasing proton concentration [40]. In contrast to this, electron transfer from $\mathrm{QuPh}^{\circ}-\mathrm{NA}$ to MNPs occurs without assistance of proton because of the much stronger reducing ability of $\mathrm{QuPh}{ }^{\circ}-\mathrm{NA}$ as compared with
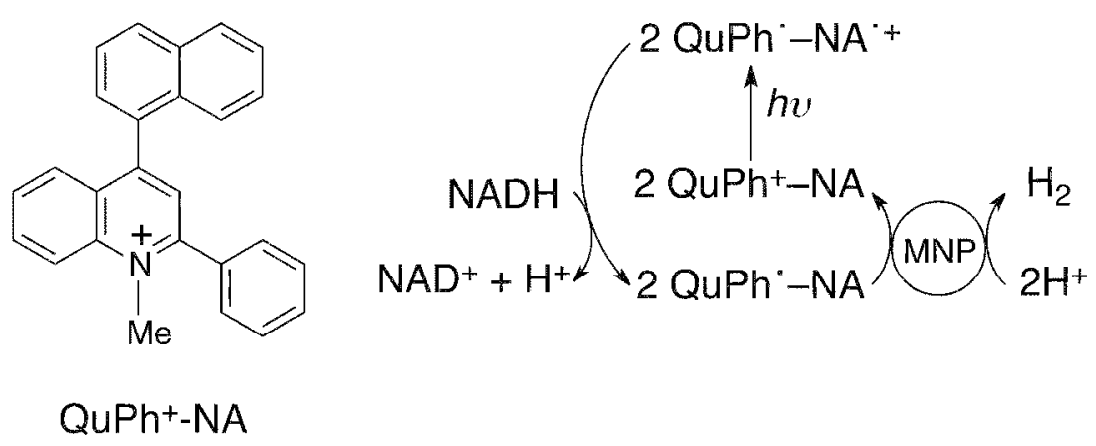

Scheme 5. Structure of $\mathrm{QuPh}^{+}-\mathrm{NA}$ and the overall catalytic cycle for the photocatalytic hydrogen evolution with $\mathrm{QuPh}^{+}-\mathrm{NA}$ and metal nanoparticles (MNPs, $\mathrm{M}=\mathrm{Ru}, \mathrm{Pt}$ ).

Acr-Mes judging from the significantly more negative oxidation potential of $\mathrm{QuPh}^{\circ}-$ $\mathrm{NA}\left(E_{\mathrm{ox}}=-0.90 \mathrm{~V}\right.$ vs SCE$)$ than that of Acr - Mes $\left(E_{\mathrm{ox}}=-0.57 \mathrm{~V}\right.$ vs SCE $)$ [37]. Thus, the 
rate of electron transfer from $\mathrm{QuPh}^{\circ}-\mathrm{NA}$ to $\mathrm{MNPs}$ remains about the same even under highly basic conditions ( $\mathrm{pH} 10)$. RuNPs could be replaced by NiNPs, which are more earth abundant, although the catalytic reactivity was $40 \%$ of that with commercially available PtNPs using the same catalyst weight [42].

$\mathrm{NADH}$ used as an electron and proton donor in Scheme 5 has been replaced by oxalic acid for the photocatalytic $\mathrm{H}_{2}$ production with $\mathrm{QuPh}^{+}-\mathrm{NA}$ in a deaerated mixed solution $[1: 1(\mathrm{v} / \mathrm{v})]$ of an aqueous buffer $(\mathrm{pH} 6.0)$ and acetonitrile [43]. Oxalate and its conjugate acid can act as a two-electron donor to produce two equivalents of $\mathrm{CO}_{2}$ and hydrogen (eq 1). In this case as well, the catalytic reactivity of NiNPs was $32 \%$ of PtNPs [43].

$(\mathrm{COOH})_{2} \rightarrow 2 \mathrm{CO}_{2}+\mathrm{H}_{2}$

A mixed solution of acetonitrile and water was used in the above reaction (eq 1), because of the insolubility of $\mathrm{QuPh}^{+}-\mathrm{NA}$ in water. In order to perform the photocatalytic production of $\mathrm{H}_{2}$ in water, $\mathrm{QuPh}^{+}-\mathrm{NA}$ was incorporated into nanosized mesoporous silica-alumina with a spherical shape (sAlMCM-41) by cation exchange and the composite $\left(\mathrm{QuPh}^{+}-\mathrm{NA} @\right.$ sAlMCM-41) was employed as a photocatalyst in water [44]. Incorporation of cationic electron donor-acceptor dyads into nanosized mesoporous silica-alumina was reported to result in much longer lifetimes of the photogenerated electron-transfer states as compared with those in solution $[45,46]$. The size and morphology of sAlMCM-41 were confirmed by TEM measurements and all particles were spherical and the particles sizes ranged from 200 to $700 \mathrm{~nm}$ [44]. In this case, $\mathrm{K}_{2} \mathrm{PtCl}_{6}$ was used as a precursor catalyst for PtNPS, because PtNPs could not be incorporated into sAlMCM-41 due to the larger size of PtNPs than the window size of sAlMCM-41 [44]. No $\mathrm{H}_{2}$ evolution was observed under photoirradiation $(\lambda>340 \mathrm{~nm})$ of a phthalate buffer ( $\mathrm{pH} 4.5$ ) dispersion containing $\mathrm{QuPh}^{+}-\mathrm{NA} @$ sAlMCM-41, sodium 
oxalate and PtNPs as a photosensitizer, a sacrificial electron donor and an $\mathrm{H}_{2}$-evolution catalyst, respectively [44]. When $\mathrm{K}_{2} \mathrm{PtCl}_{6}$ was added to the reaction solution instead of PtNPs as a precursor of $\mathrm{H}_{2}$-evolution catalyst, however, efficient $\mathrm{H}_{2}$ production was observed [44]. $\mathrm{Cu}\left(\mathrm{NO}_{3}\right)_{2}$ also acted as a precursor catalyst for the photocatalytic $\mathrm{H}_{2}$ production with oxalate in water $(\mathrm{pH} 4.5)$ [44]. Thus, hybrid $\mathrm{H}_{2}$-evolution catalysts derived from earth-abundant metal salts in situ provide a convenient way to develop efficient water reduction catalysts working in water as shown in Figure 2.

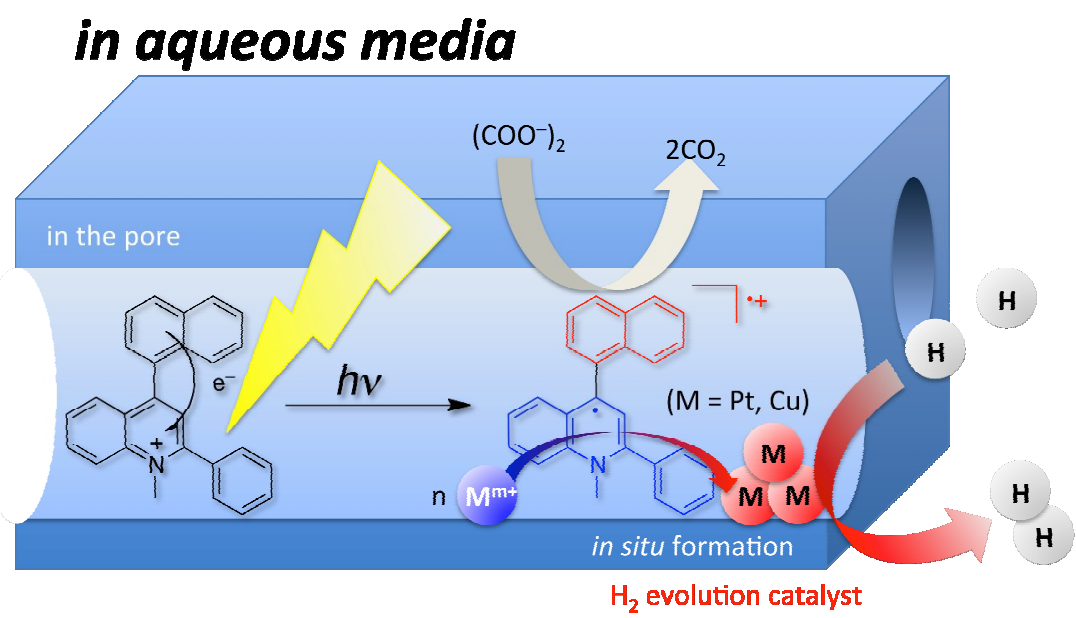

Figure 2. Photocatalytic production of $\mathrm{H}_{2}$ from oxalate with $\mathrm{QuPh}^{+}-\mathrm{N}$ incorporated into nanosized mesoporous silica-alumina (sAlMCM-41) and $\mathrm{Pt}$ or $\mathrm{Cu}$ salts as precursor catalysts.

Under acidic conditions, oxalate anion is protonated to produce oxalic acid, which cannot act as an electron donor in the photocatalytic $\mathrm{H}_{2}$ production system (vide supra). However, a composite photocatalytic system employing acidic oxalic acid as an electron donor has been successfully constructed by combining $\mathrm{QuPh}^{+}-\mathrm{NA}$, Pt and nanosheets prepared by exfoliation of $\mathrm{K}_{4} \mathrm{Nb}_{6} \mathrm{O}_{17}$ (niobate-NS) as an organic photosensitiser, a hydrogen-evolution catalyst and a semiconductor photocatalyst for oxidation of oxalic acid, respectively [47]. The composite photocatalyst, $\mathrm{QuPh}^{+}-\mathrm{NA} /$ niobate-NS (Pt), was prepared by a two-step route to locate a $\mathrm{Pt}$ catalyst near $\mathrm{QuPh}^{+}-\mathrm{NA}$ on the surfaces of 
niobate-NS [47]. $\mathrm{QuPh}^{+}-\mathrm{NA}$ was supported on niobate-NS by a cation exchange method and then Pt was supported on the $\mathrm{QuPh}^{+}-\mathrm{NA} /$ niobate-NS by a photodeposition method using $\mathrm{PtCl}_{4}{ }^{2-}$ as a precursor, which repulsively interacts with the negatively charged surfaces of niobate-NS [47]. The precursor of $\mathrm{PtCl}_{4}{ }^{2-}$ was reduced to metallic Pt by the photocatalysis of $\mathrm{QuPh}^{+}-\mathrm{NA}$ in the presence of oxalic acid. Photocatalytic $\mathrm{H}_{2}$ evolution with the composite catalyst proceeds via photoexcitation of both niobate-NS and $\mathrm{QuPh}^{+}-\mathrm{NA}$ to produce an electron and a hole in the semiconductor and the electrontransfer state $\left(\mathrm{QuPh}^{\circ}-\mathrm{NA}^{\bullet+}\right)$, respectively [47].

\section{Interconversion between $\mathrm{H}_{2}$ and hydrogen storage compounds}

Although $\mathrm{H}_{2}$ is a promising renewable energy resource as an alternative to fossil fuels, storage and transportation of $\mathrm{H}_{2}$ are quite difficult, because $\mathrm{H}_{2}$ gas is explosive and its volumetric energy density is very low [48]. In the natural photosynthesis of plants, electrons and protons taken from water using solar energy are used to reduce $\mathrm{NAD}(\mathrm{P})^{+}$ to $\mathrm{NAD}(\mathrm{P}) \mathrm{H}$, which can reductively fix $\mathrm{CO}_{2}$ [1]. In hydrogenase-containing photosynthetic organisms such as cyanobacteria, electrons and protons taken from water using solar energy are used for the reduction of protons to hydrogen $\left(\mathrm{H}_{2}\right)$ rather than the reduction of $\mathrm{NAD}(\mathrm{P})^{+}$to $\mathrm{NAD}(\mathrm{P}) \mathrm{H}[8]$. Both the oxidation of $\mathrm{H}_{2}$ with $\mathrm{NAD}(\mathrm{P})^{+}$and the reduction of protons with $\mathrm{NAD}(\mathrm{P}) \mathrm{H}$ are catalyzed by hydrogenases [11]. There has been much effort to develop hydrogenase functional mimics, which are able to reduce protons to $\mathrm{H}_{2}$ or to oxidize $\mathrm{H}_{2}$ to protons [19,50-52].

Interconversion between the oxidation of $\mathrm{H}_{2}$ with $\mathrm{NAD}(\mathrm{P})^{+}$to produce protons and $\mathrm{NAD}(\mathrm{P}) \mathrm{H}$ and the reduction of protons with $\mathrm{NAD}(\mathrm{P}) \mathrm{H}$ to produce $\mathrm{H}_{2}$ and $\mathrm{NAD}(\mathrm{P})^{+}$in an aqueous solution has been made possible by using a $[\mathrm{C}, \mathrm{N}]$ cyclometalated organoiridium complex $\left(\left[\operatorname{Ir}^{\mathrm{III}}\left(\mathrm{Cp}^{*}\right)\left(4-\left(1 \mathrm{H}-\text { pyrazol-1-yl- } \kappa N^{2}\right) \text { benzoic acid- } \kappa C^{3}\right)\left(\mathrm{H}_{2} \mathrm{O}\right)\right]_{2}\right.$ $\mathrm{SO}_{4}$ ) and by changing $\mathrm{pH}$ under an atmospheric pressure of $\mathrm{H}_{2}$ at room temperature [52]. Under slightly acidic conditions $(\mathrm{pH}=4.1)$, the $\mathrm{Ir}^{\mathrm{III}}-\mathrm{H}_{2} \mathrm{O}$ complex (1) reacts with 
NADH to produce the hydride complex $\left(\left[\mathrm{M}_{1}-\mathrm{H}\right]^{0}\right)$, which reacts with $\mathrm{H}_{3} \mathrm{O}^{+}$to produce $\mathrm{H}_{2}$, accompanied by regeneration of $\mathbf{1}$ (Scheme 6) [52]. The turnover frequency (TOF) was $44 \mathrm{~h}^{-1}$. At $\mathrm{pH} 6.5$, the carboxylic acid group of $\mathbf{1}$ is deprotonated to produce $\left[\mathrm{M}_{2}\right.$ $\left.\mathrm{H}_{2} \mathrm{O}\right]$ (2), which reacts with $\mathrm{H}_{2}$ to produce the hydride complex $\left(\left[\mathrm{M}_{2}-\mathrm{H}\right]^{-}\right)$, and then the hydride complex reacts with $\mathrm{NAD}^{+}$to produce $\mathrm{NADH}$, accompanied by regeneration of 2 (Scheme 6) with TOF $=36 \mathrm{~h}^{-1}$ [52]. Thus the water soluble Ir complex $(\mathbf{1}$ or $\mathbf{2})$ acts as an efficient catalyst for interconversion between $\mathrm{H}_{2}$ and $\mathrm{NADH}$

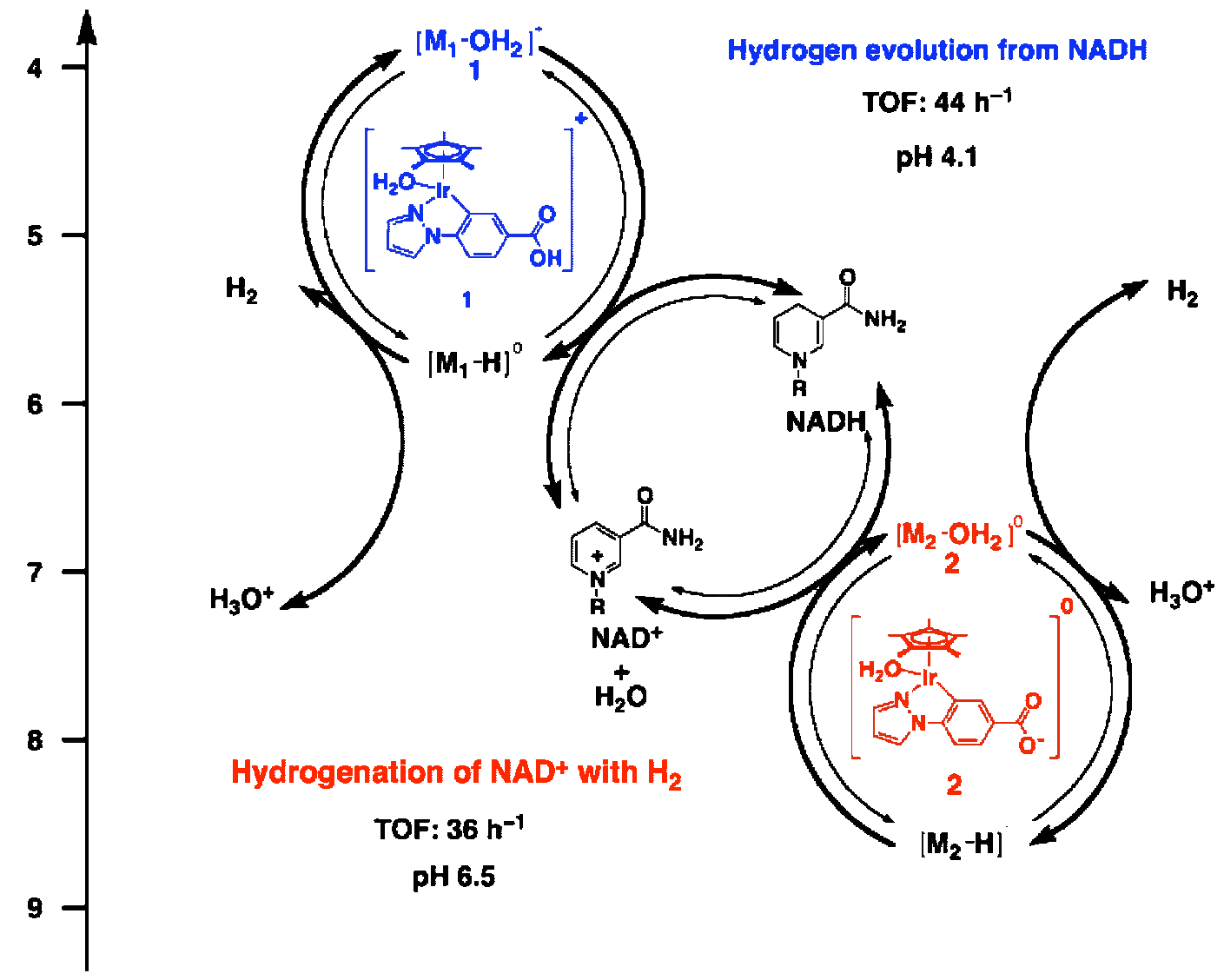

Scheme 6. Catalytic mechanism for interconversion between NADH and $\mathrm{H}_{2}$ with a water soluble $[\mathrm{C}, \mathrm{N}]$ cyclometalated Ir complexes (1 and $\mathbf{2})$ depending on $\mathrm{pH}$.

(biological equivalent of $\mathrm{H}_{2}$ ) at ambient pressure and temperature depending on $\mathrm{pH}$. 
Interconversion between $\mathrm{H}_{2}$ and formic acid $(\mathrm{HCOOH})$ in water at ambient temperature and pressure (eq 2) has also been made possible by using the same Ir catalyst (1 or 2 ) employed in Scheme 6 as an efficient catalyst for both directions depending on $\mathrm{pH}$ $[53,54]$. Formic acid efficiently decomposes to afford $\mathrm{H}_{2}$ and $\mathrm{CO}_{2}$ in the presence of 1 in acidic water ( $\mathrm{pH} 2.8$ ), whereas hydrogenation of $\mathrm{CO}_{2}$ by $\mathrm{H}_{2}$ occurs in the presence of 2 under an atmospheric pressure of $\mathrm{H}_{2}$ and $\mathrm{CO}_{2}$ in weakly basic water $(\mathrm{pH} 7.5)$ at room temperature [53]. Thus, $\mathrm{HCOOH}$ can be regarded as a liquid form of $\mathrm{H}_{2}$ with relatively high volumetric density $\left(d=1.22 \mathrm{~g} \mathrm{~cm}^{-3}\right)$.

\section{$\mathrm{CO}_{2}+\mathrm{H}_{2} \rightleftarrows \mathrm{HCOOH}$}

The same Ir catalyst (1) can also act as an efficient catalyst for decomposition of paraformaldehyde to produce $\mathrm{H}_{2}$ and $\mathrm{CO}_{2}$ in a 2:1 mol ratio under basic conditions at room temperature [55]. At $\mathrm{pH} 11, \mathbf{1}$ is converted to the hydroxo complex $\mathbf{3}$, which reacts with paraformaldehyde $\mathrm{HO}\left(\mathrm{CH}_{2} \mathrm{O}\right)_{n} \mathrm{H}$ via the monomerized and hydrated equivalent, methanediol [56], to produce the formaldehyde adduct ([Ir-OCH$\left.\left.{ }_{2} \mathrm{OH}\right]^{-}\right)$and $\mathrm{HO}\left(\mathrm{CH}_{2} \mathrm{O}\right)_{\mathrm{n}-1} \mathrm{H}$ [55]. The $\beta$-hydrogen elimination from $\left[\mathrm{Ir}-\mathrm{OCH}_{2} \mathrm{OH}\right]^{-}$occurs to produce the hydride complex (4) and formic acid. The hydride complex (4) reacts with $\mathrm{H}_{2} \mathrm{O}$ to produce $\mathrm{H}_{2}$, accompanied by regeneration of $\mathbf{3}$ (upper-side catalytic cycle in Scheme 7) [55]. The hydroxo complex 3 also reacts with formate to produce the hydride complex (4) and $\mathrm{CO}_{2}$ by $\beta$-hydrogen elimination. The hydride complex (4) also reacts with $\mathrm{H}_{2} \mathrm{O}$ to produce $\mathrm{H}_{2}$, accompanied by regeneration of $\mathbf{3}$ (lower-side catalytic cycle in Scheme 7) [55]. Thus, paraformaldehyde can be regarded as a convenient solid $\mathrm{H}_{2}$ carrier, which has a higher energy density (6.7\%) than $\mathrm{HCOOH}(4.4 \%)$. 


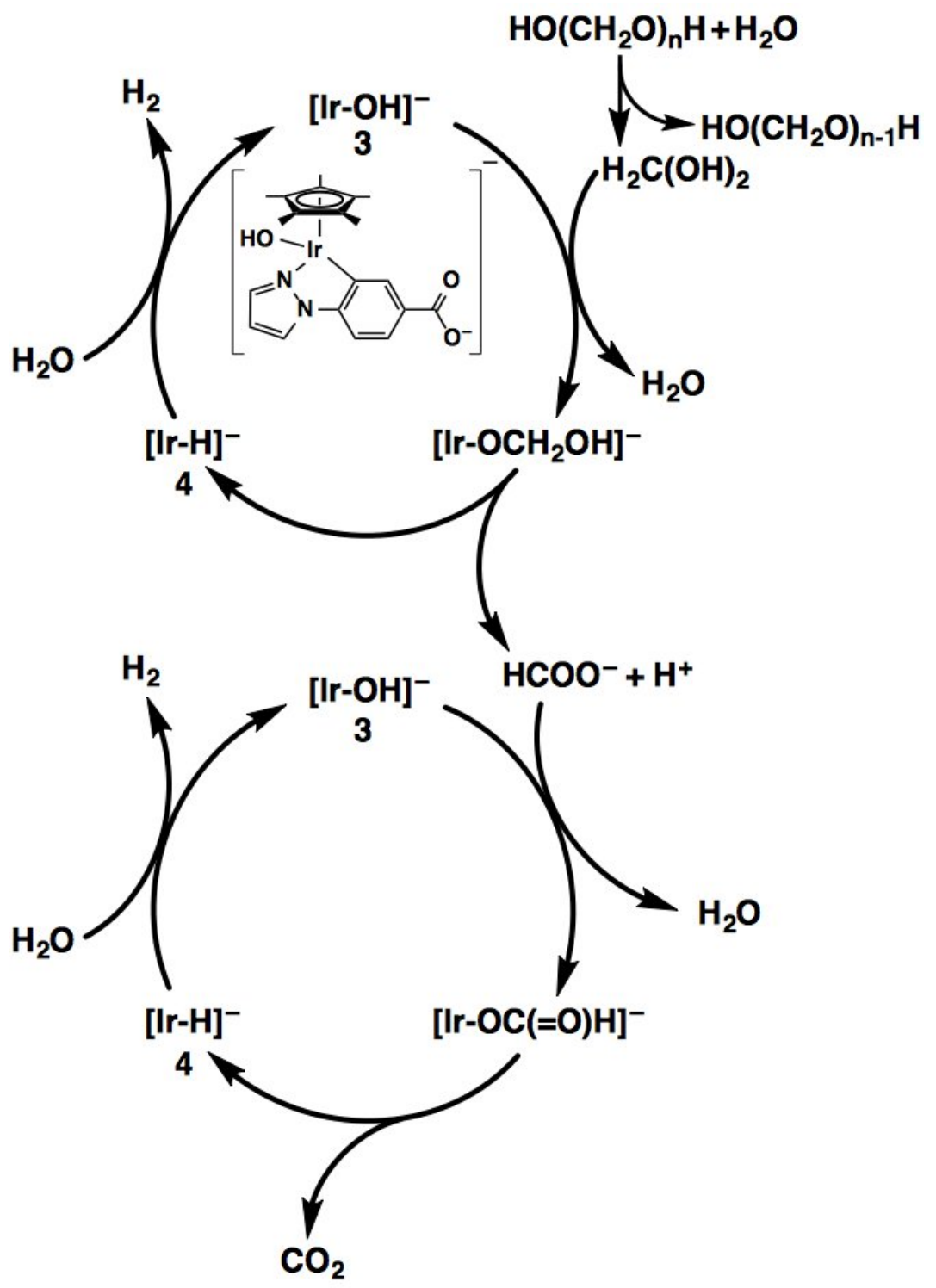

Scheme 7. Catalytic cycles for decomposition of paraformaldehyde to $\mathrm{H}_{2}$ and formate that is further decomposed to $\mathrm{H}_{2}$ and $\mathrm{CO}_{2}$ with 3 .

\section{Conclusions}

Recent advances in artificial photosynthesis for production of $\mathrm{H}_{2}$ and storage of $\mathrm{H}_{2}$ as liquid and solid forms have provided valuable insights on the biomimetic catalysts of combination of PSI and hydrogenases. Efficient photocatalytic production of $\mathrm{H}_{2}$ has been made possible by using earth-abundant materials as catalysts. The catalytic 
interconversion between gaseous $\mathrm{H}_{2}$ and $\mathrm{H}_{2}$ storage compounds (liquid or solid) has also been made possible at ambient pressure and temperature. The resulting insights are highly desired to be combined with biomimetic catalysis of PSII for water oxidation to produce $\mathrm{H}_{2}$ from water used as electron and proton source in the near future. The challenging issue required for practical applications to produce solar fuels as an alternative to fossil fuels is the combination of efficient photocatalytic water oxidation and reduction catalysts. Recent development of robust and highly efficient molecular electrocatalysis using $\mathrm{Ni}$ and $\mathrm{Co}$ complexes [57,58] provides valuable insights into more efficient energy storage and utilization.

\section{Acknowledgements}

The authors are most grateful to the collaborators and coworkers who performed the researches reported in this article and support by a Grant-in-Aid from MEXT and an ALCA project from JST, Japan。

\section{References and recommended reading}

Papers of particular interest, published within the period of review, have been highlighted as:

- of special interest

•• of outstanding interest

1. Nelsen N: Photosystems and global effects of oxygenic photosynthesis. Biochim Biophys Acta 2011, 1807:856-863.

2. Lewis NS, Nocera DG: Powering the planet: Chemical challenges in solar energy utilization. Proc Natl Acad Sci USA 2006, 103:15729-15735.

3. Gust D, Moore TA, Moore AL: Solar fuels via artificial photosynthesis. Acc Chem Res 2009, 42:1890-1898.

4. Wasielewski MR: Self-assembly strategies for integrating light harvesting and 
charge separation in artificial photosynthetic systems. Acc Chem Res 2009, 42: 1910-1921.

5. Fukuzumi S, Ohkubo K: Assemblies of artificial photosynthetic reaction centers. J Mater Chem 2012, 22:4575-4587.

6. Fukuzumi S, Ohkubo K, Suenobu T: Long-lived charge separation and applications in artificial photosynthesis. Acc Chem Res 2014, 47:1455-1464.

7. Wu LZ, Chen B, Li ZJ, Tung CH: Enhancement of the efficiency of photocatalytic reduction of protons to hydrogen via molecular assembly. Acc Chem Res 2014, 47:2177-2185.

8. Kufryk G, Advances in utilizing cyanobacteria for hydrogen production. Adv in Microbiol 2013, 3:60-68.

9. King PW: Designing interfaces of hydrogenase-nanomaterial hybrids for efficient solar conversion. Biochim Biophys Acta 2013, 1827:949-957.

10. Photosystem I: The light-driven plastocyanin:ferredoxin oxidoreductase. Edited by Golbeck JH. Dordrecht: Springer; 2006.

11. Lubitz W, Ogata, H, Rüdiger, O, Reijerse, E: Hydrogenases. Chem Rev 2014, 114:4081-4148.

12. Stiebritz MT, Reiher M: Hydrogenases and oxygen. Chem Sci 2012, 3:1739-1751.

13. • Fukuzumi S, Yamada Y, Suenobu T, Ohkubo K, Kotani H: Catalytic mechanisms of hydrogen evolution with homogeneous and heterogeneous catalysts. Energy Environ Sci 2011, 4: 2754-2766. This perspective article summarized reaction mechanisms of hydrogen $\left(\mathrm{H}_{2}\right)$ evolution with homogeneous and heterogeneous catalysts based on kinetic studies including kinetic isotope effects.

14. Simmons TR, Berggren G, Bacchi M, Fontecave M, Artero V: Mimicking hydrogenases: From biomimetics to artificial enzymes. Coord. Chem. Rev. 2014, 270-271:127-150.

15. •- Ogo S, Kabe R, Uehara K, Kure B, Nishimura T, Menon SC, Harada R, Fukuzumi S, Higuchi Y, Ohhara T, Tamada T, Kuroki R: A dinuclear Ni( $\mu$-H)Ru complex derived from $\mathbf{H}_{2}$. Science 2007, 316:585-587 A paramagnetic dinuclear nickel-ruthenium complex with a bridging hydrido ligand from the heterolytic cleavage of $\mathrm{H}_{2}$ by a dinuclear $\mathrm{NiRu}$ aqua complex in water under ambient conditions. The structure of the hexacoordinate $\mathrm{Ni}(\mu-\mathrm{H}) \mathrm{Ru}$ complex was unequivocally determined by neutron diffraction analysis. The results suggest that 
the $\mathrm{RuNiH}$ core could be described as $\mathrm{Re}-\mathrm{H}^{-} \bullet \cdot \mathrm{Ni}$, which indicates that the $\mathrm{Ni}$ (II) serves as a Lewis acid to stabilize the hydride. Such insights would otherwise be unattainable by studies on the enzyme itself, because protein crystallography cannot detect hydride ligands.

16. - Ogo S, Ichikawa K, Kishima T, Matsumoto T, Nakai H, Kusaka K, Ohhara T: A Functional [NiFe]hydrogenase mimic that catalyzes electron and hydride transfer from $\mathbf{H}_{2}$. Science 2013, 339:682-684 This paper report the first structural and functional $[\mathrm{NiFe}]$-based model of [NiFe]hydrogenase enzymes. The neutronscattering analysis revealed that the hydride ion was located on the Fe center. This complex heterolytically activates hydrogen to form a hydride complex that is capable of reducing substrates by either hydride ion or electron transfer.

17. - Fukuzumi S, Yamada Y: Catalytic activity of metal-based nanoparticles for photocatalytic water oxidation and reduction. J Mater Chem 2012, 22:2428424296. This feature article focuses on the catalytic activity of non-Pt metal nanoparticles for the photocatalytic $\mathrm{H}_{2}$ production from water as well as water oxidation.

18. - Fukuzumi S, Hong D, Yamada Y: Bioinspired photocatalytic water reduction and oxidation with earth-abundant metal catalysts. J Phys Chem Lett 2013, 4:3458-3467. This perspective article summarized the development of earthabundant metal catalysts for photocatalytic water reduction and oxidation, inspired by structure and functions of hydrogenases and oxygen evolving center in PSII.

19. - Fukuzumi S, Suenobu T: Hydrogen storage and evolution catalysed by metal hydride complexes. Dalton Trans 2013, 42:18-28. This perspective article summarized the current status of $\mathrm{H}_{2}$ storage and evolution using various hydrogen donors (formic acid, NADH and alcohols), which are catalyzed by metal hydride complexes. The catalytic mechanisms of the $\mathrm{H}_{2}$ storage and evolution are discussed by focusing on the reactivity of metal-hydride complexes.

20. Lubner CE, Grimme R, Bryant DA, Golbeck JH: Wiring photosystem I for direct solar hydrogen production. Biochemistry 2010, 49:404-414.

21. SBtif, P: Ferredoxin and flavodoxin reduction by photosystem 1. Biochim Biophys Acta 2001, 1507:161-179.

22. - Ihara M, Nishihara H, Yoon KS, Lenz O, Friedrich B, Nakamoto H, Kojima K, Honma D, Kamachi T, Okura I: Light-driven hydrogen production by a hybrid 
complex of a [NiFe]-hydrogenase and the cyanobacterial photosystem I. Photochem Photobiol 2006, 82: 676-682 This paper reports the first example of a light-driven $\mathrm{H} 2$ production by an artificial complex between a [NiFe]-hydrogenase and the cyanobacterial PSI, representing an important step on the way to design a photosynthetic organism that efficiently converts solar energy and water into $\mathrm{H}_{2}$.

23. Ihara M, Nakamoto H, Kamachi T, Okura I, Maeda M: Photoinduced hydrogen production by direct electron transfer from photosystem I cross-linked with cytochrome $c_{3}$ to [NiFe]-hydrogenase. Photochem Photobiol 2006, 82:16771685.

24. Greenbaum E: Platinized chloroplasts: A novel photocatalytic material. Science 1985, 230:1373-1375.

25. Utschig LM, Dimitrijevic NM, Poluektov OG, Chemerisov SD, Mulfort KL, Tiede DM: Photocatalytic hydrogen production from noncovalent biohybrid photosystem I/Pt nanoparticle complexes. J Phys Chem Lett 2011, 2:236-241.

26. Grimme RA, Lubner $\mathrm{CE}$, Golbeck JH: Maximizing $\mathbf{H}_{2}$ production in photosystem I/dithiol molecular wire/platinum nanoparticle bioconjugates. Dalton Trans 2009, 10106-10113.

27. Gorka M, Schartner J, van der Est A, Rögner M, Golbeck JH: Light-mediated hydrogen generation in photosystem $I$ : Attachment of a naphthoquinonemolecular wire-Pt nanoparticle to the $\mathbf{A}_{1 \mathrm{~A}}$ and $\mathbf{A}_{1 \mathrm{~B}}$ sites. Biochemistry 2014, 53:2295-2306.

28. Brown KA, Wilker MB, Boehm M, Dukovic G, King PW: Characterization of photochemical processes for $\mathrm{H}_{2}$ production by $\mathrm{CdS}$ nanorod-[FeFe] hydrogenase complexes. J Am Chem Soc 2012, 134:5627-5636.

29. Wilker MB, Shinopoulos KE, Brown KA, Mulder DW, King PW, Dukovic G: Electron transfer kinetics in CdS nanorod-[FeFe]-hydrogenase complexes and implications for photochemical $\mathbf{H}_{2}$ generation. J Am Chem Soc 2014, 136:43164324.

30. Brown GM, Brunschwig BS, Creutz C, Endicott JF, Sutin N: Homogeneous catalysis of the photoreduction of water by visible light. Mediation by a tris(2,2'-bipyridine)ruthenium(II)-cobalt(II) macrocycle system. J Am Chem Soc 1979, 101:1298-1300.

31. Grätzel M: Artificial photosynthesis: water cleavage into hydrogen and oxygen 
by visible light. Acc Chem Res 1981, 14:376-384.

32. Darwent JR, Douglas P, Harriman A, Porter G, Richoux MC: Metal phthalocyanines and porphyrins as photosensitizers for reduction of water to hydrogen. Coord Chem Rev 1982, 44:83-126.

33. Deponti E, Luisa A, Natali M, Iengo E, Scandola F: Photoinduced hydrogen evolution by a pentapyridine cobalt complex: elucidating some mechanistic aspects. Dalton Trans 2014, in press DOI: 10.1039/c4dt02269f

34. Lv H, Guo W, Wu K, Chen Z, Bacsa J, Musaev DG, Geletii YV, Lauinger SM, Lian T, Hill CL: A noble-metal-free, tetra-nickel polyoxotungstate catalyst for efficient photocatalytic hydrogen evolution. J Am Chem Soc 2014, 136:1401514018.

35. - Fukuzumi S, Kobayashi T, Suenobu T: Photocatalytic production of hydrogen by disproportionation of one-electron-reduced rhodium and iridiumruthenium complexes in water. Angew Chem Int Ed 2011, 50:728-731 This paper clarified how photoinduced electron transfer of a photosensitizer (a one-electron process) leads to $\mathrm{H}_{2}$ production (a two-electron process) via disproportionation of the one-electron-reduced metal complexes.

36. - Fukuzumi S, Kotani H, Ohkubo K, Ogo S, Tkachenko NV, Lemmetyinen H: Electron-transfer state of 9-mesityl-10-methylacridinium ion with a much longer lifetime and higher energy than that of natural photosynthetic reaction center. J Am Chem Soc 2004, 126:1600-1601 This paper reports the first example of a simple electron donor-acceptor dyad (9-mesityl-10-methylacridinium ion) affording the photogenerated electron-transfer state, which has a much longer lifetime and higher energy than that of the photosynthetic reaction center, by minimizing the reorganization energy of electron transfer without loss of energy due to multistep electron-transfer processes.

37. Kotani H, Ohkubo K, Fukuzumi S: Formation of a long-lived electron-transfer state of a naphthalene-quinolinium ion dyad and the $\pi$-dimer radical cation. Faraday Discuss 2012, 155:89-102.

38. Kotani H, Ohkubo K, Takai Y, Fukuzumi S: Viologen-modified platinum clusters acting as an efficient catalyst in photocatalytic hydrogen evolution. $J$ Phys Chem B 2006, 110:24047-24053.

39. Kotani H, Ono T, Ohkubo K, Fukuzumi S: Efficient photocatalytic hydrogen evolution without an electron mediator using a simple electron donor-acceptor 
dyad. Phys Chem Chem Phys 2007, 9:1487-1492.

40. Kotani H, Hanazaki R, Ohkubo K, Yamada Y, Fukuzumi S: Size- and shapedependent activity of metal nanoparticles as hydrogen-evolution catalysts: Mechanistic insights into the electron-transfer injection step. Chem Eur J 2011, 17:2777-2785.

41. - Yamada Y, Miyahigashi T, Kotani H, Ohkubo K, Fukuzumi S: Photocatalytic hydrogen evolution under highly basic conditions by using $R u$ nanoparticles and 2-phenyl-4-(1-naphtyl)quinolinium ion. J Am Chem Soc 2011, 133:1613616145. Photocatalytic hydrogen evolution with a ruthenium metal catalyst under basic conditions ( $\mathrm{pH} 10)$ has been made possible for the first time by using 2phenyl-4-(1-naphthyl)- quinolinium ion $\left(\mathrm{QuPh}^{+}-\mathrm{NA}\right), \mathrm{NADH}$, and $\mathrm{Ru}$ nanoparticles (RuNPs) as the photocatalyst, electron donor, and hydrogenevolution catalyst, respectively. RuNPs have been demonstrated to exhibit comparable catalytic activity to PtNPs.

42. Yamada Y, Miyahigashi T, Kotani H, Ohkubo K, Fukuzumi S: Photocatalytic hydrogen evolution with $\mathrm{Ni}$ nanoparticles by using 2-phenyl-4-(1naphthyl)quinolinium ion as a photocatalyst. Energy Environ Sci 2012, 5:61116118.

43. Yamada Y, Miyahigashi M, Ohkubo K, Fukuzumi S: Photocatalytic production of hydrogen with 2-phenyl-4-(1-naphthyl)-quinolinium ion and oxalate. Phys Chem Chem Phys 2012, 14:10564-10571.

44. Yamada Y, Tadokoro H, Fukuzumi S: Hybrid $\mathbf{H}_{2}$-evolution catalysts: in situ formation of $\mathrm{H}_{2}$-evolution catalysts from metal salts inside mesopore of silicaalumina supporting an organic photosensitiser. RSC Adv 2013, 3:25677-25680.

45. Fukuzumi S, Doi K, Itoh A, Suenobu T, Ohkubo K, Yamada Y, Karlin KD: Formation of a long-lived electron-transfer state in nanosized mesoporous silica-alumina enhances photocatalytic oxidation reactivity with a copper complex. Proc Natl Acad Sci USA 2012, 109:15572-15577.

46. Yamada Y, Nomura A, Ohkubo K, Suenobu T, Fukuzumi S: Long-lived electron transfer state of 2-phenyl-4-(1-naphthyl)quinolinium ion incorporated into 
nanosized mesoporous silica-alumina acting as a robust photocatalyst in water. Chem Commun 2013, 49:5132-5134.

47. Yamada Y, Nomura A, Tadokoro H, Fukuzumi S: A composite photocatalyst of an organic electron donor-acceptor dyad and a Pt catalyst supported on semiconductor nanosheets for efficient hydrogen evolution from oxalic acid. Catal Sci Technol 2014, in press.

48. - Fukuzumi S: Bioinspired energy conversion systems for hydrogen production and storage. Eur J Inorg Chem 2008:1351-1362 This is a review on developments in photocatalytic hydrogen production by using artificial photosynthesis systems together with those in hydrogen storage through the fixation of $\mathrm{CO}_{2}$ with $\mathrm{H}_{2}$.

49. Magnuson, A.; Anderlund, M.; Johansson, O.; Lindblad, P.; Lomoth, R.; Polivka, T.; Ott, S.; Stensjö, K.; Styring, S.; Sundström, V.; Hammarström, L: Biomimetic and microbial approaches to solar fuel generation. Acc. Chem. Res. 2009, 42:1899-1909.

50. Kaur-Ghumaan, Sandeep; Stein, M: [NiFe] hydrogenases: How close do structural and functional mimics approach the active site? Dalton Trans. 2014, 43:9392-9405.

51. Simmons, Trevor R.; Artero, V: Catalytic hydrogen oxidation: Dawn of a new iron age. Angew. Chem., Int. Ed. 2013, 52:6143-6145.

52. - Maenaka Y, Suenobu T, Fukuzumi S: Efficient catalytic interconversion between NADH and $\mathrm{NAD}^{+}$accompanied by generation and consumption of hydrogen with a water-soluble iridium complex at ambient pressure and temperature. $J$ Am Chem Soc 2011, 134:367-374 This is the first report on catalytic interconversion between $\mathrm{NADH}$ and $\mathrm{H}_{2}$ at ambient pressure and temperature by using a $[\mathrm{C}, \mathrm{N}]$ cyclometalated organoiridium complex. The corresponding iridium hydride complex formed under an atmospheric pressure of $\mathrm{H}_{2}$ undergoes the 1,4-selective hydrogenation of $\mathrm{NAD}^{+}$to form 1,4-NADH, whereas in weakly acidic water the hydride complex formed by the reduction of the $\mathrm{Ir}(\mathrm{III})$ complex with $\mathrm{NADH}$ reacts with proton to produce $\mathrm{H}_{2}$.

53. Maenaka Y, Suenobu $T$, Fukuzumi S: Catalytic interconversion between hydrogen and formic acid at ambient temperature and pressure. Energy Environ Sci 2012, 5:7360-7367.

54. • Hull JF, Himeda Y, Wang WH, Hashiguchi B, Periana R, Szalda DJ, Muckerman 
JT, Fujita E: Reversible hydrogen storage using $\mathrm{CO}_{2}$ and a proton-switchable iridium catalyst in aqueous media under mild temperatures and pressures. Nat Chem 2012, 4: 383-388 This paper also reports that a dinuclear $\operatorname{Ir}\left(\mathrm{Cp}^{*}\right)$ complex with 4,4',6,6'-tetrahydroxy-2,2'-bipyrimidine (thbpym) as a bridging ligand, $\left[\left\{\operatorname{Ir}\left(\mathrm{Cp}^{*}\right)(\mathrm{Cl})\right\}_{2}(\text { thbpym })\right]^{2+}$, acts as a $\mathrm{pH}$-modulated catalyst for interconversion between $\mathrm{H}_{2}$ and $\mathrm{HCOOH}$ by the deprotonation equilibrium of the phenolic ligand.

55. Suenobu T, Shibata S, Fukuzumi S: Catalytic hydrogen production from paraformaldehyde and water with an organoiridium complex. Chem Commun 2014 , in press.

56. Nielsen M, Alberico E, Baumann W, Drexler HJ, Junge H, Gladiali S, Beller M: Low-temperature aqueous-phase methanol dehydrogenation to hydrogen and carbon dioxide. Nature 2013, 495: 85-89.

57. DuBois DL: Development of molecular electrocatalysts for energy storage. Inorg. Chem. 2014, 53: 3935-3960.

58. Bullock RM, Appel AM, Helm ML: Production of hydrogen by electrocatalysis: making the H-H bond by combining protons and hydrides. Chem. Commun. 2014, 50: $3125-3143$. 